\title{
The Quest for Better Structural Steels
}

\author{
Panagiotis Sismanis ${ }^{1 *}$ and Spyros Papaefthymiou ${ }^{2}$ \\ ${ }^{1}$ Sidenor SA, Greece \\ ${ }^{2}$ National Technical University of Athens, Greece
}

Submission: October 10, 2018; Published: October 17, 2018

*Corresponding author: Panagiotis Sismanis, Sidenor SA, Greece; Tel: +30-210-678-7747; Email: psismanis@sidenor.vionet.gr

\begin{abstract}
Structural steel grades are widely used in civil engineering applications in various product forms (bar or plates). Through the years focus is laid on how to obtain higher strength in combination with improved impact properties. In parallel, properties such as bendability and weldability are also considered. In this way, constructions comply with raising demands on improved performance under extreme conditions. A good way to achieve this is through the modification of phase transformations. This was achieved either via the Tempcore process, by which a martensitic and/or bainitic microstructure is obtained in the outer surface of the reinforcing bar. This high strength microstructure increases yield strength but reduces albeit ductility. Thus, its volume fraction has to be controlled. The ferritic/pearlitic core of the rebar is responsible for obtaining satisfactory elongation values. Moreover, microalloying elements such as vanadium (V), niobium (Nb), titanium (Ti) are added in steels to produce a finer-grained microstructure, which increases the yield strength obeying the Hall - Petch equation while preserving higher elongation values. Nowadays, the need for tailored, more homogeneous microstructures with improved mechanical and technological properties, pave the way for the utilization of micro-alloyed steel bar and plate products.
\end{abstract}

Keywords: Structural steels; HSLA steels; Tempcore process; Yield strength; Microalloying elements, Pearlitic core

Abbreviations: HSLA: High Strength Low Alloy; YS: Yield Strength; Ceq: carbon equivalent; YSHP: Hall-Petch Yield Strength; V: Vanadium; Mo: Molybdenum

\section{Opinion}

The civil engineering community continuously demands structural reinforcing beams, bars, and plates with superior strength properties and improved behavior in various applications. The main targets do not rely upon improved bendability and weldability, higher tensile-to-yield strength ratios, or better impact strengths only; the quest for improved behavior at extreme conditions, e.g. endurance at severe environments (low or high temperatures, corrosion, fire) and dynamic loadings, e.g. seismic resistance and/or integrity assurance after malicious actions, complete the picture [1,2]. From the early development days, metallurgists and materials scientists concentrated their alloy design focusing on two significant elements-carbon and manganese. These two chemical elements were the most important amongst others and were used as the main strengthening additions in steel in combination with traditional heat treatment schemes $[3,4]$.

By the proper adjustment of their contents in liquid steel, the specified properties were more-or-less attained. The next step was to optimize the usage of these constituents by reducing their consumption either by adjusting the chemical analysis or by improving the steel microstructure. This brief opinion paper presents the prospects of structural steel development in countries with intense seismic activity taking into considerations emerging society needs, environment preservation and production security in turns of raw materials, process developments and production cost. An outlook is presented on what it appears now to be a reasonable and expected evolution following current trends and optimization of relevant steel grades on the field. The category of value-added special steels has come up with some very appealing products that draw their origin from High Strength Low Alloy (HSLA) steel grades [5,6]. Table 1 presents the steel definitions with respect to carbon ranges for clarification purposes.

Table 1: Steel definitions for carbon steels.

\begin{tabular}{|c|c|}
\hline Definition & Carbon Range \\
\hline Low Carbon Steel & $0<\mathrm{wt} \% \mathrm{C} \leq 0.15$ \\
\hline Medium-Low Carbon Steel & $0.15<\mathrm{wt} \% \mathrm{C} \leq 0.23$ \\
\hline Medium-High Carbon Steel & $0.23<\mathrm{wt} \% \mathrm{C} \leq 0.44$ \\
\hline High Carbon Steel & $\mathrm{wt} \% \mathrm{C}>0.44$ \\
\hline
\end{tabular}

In the past years, the steel rebars that were classified in the range of 400-460 MPa for the yield stress (YS) were produced from medium-high or even high carbon steels. Besides CMn steel products, micro-alloyed steel rebars were produced by adding vanadium (and/or niobium) but sold at a less competent price [7]. However, the need for increased weldability forced steel producers to seek solutions that would lower the carbon equivalent $\left(\mathrm{C}_{\mathrm{eq}}\right.$, see eq. 1$)$ and still retain mechanical properties. A more homogeneous, fine-grained steel microstructure serves 


\section{Civil Engineering Research Journal}

both needs: lowering C-Mn levels and in parallel improve weld- \& bend-ability and retain high strength [8].

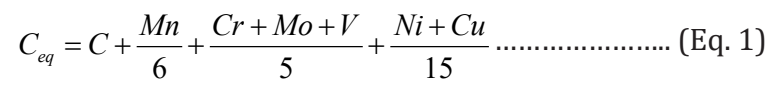

The generalized weldability criterion dictates that $\mathrm{C}_{\mathrm{eq}}$ should not exceed $0.45-0.50(\max )$, approximately. High productive industrial processes with the most representative being Tempcore managed to match the mechanical properties target and in parallel to shift the carbon footprint of the produced rebar to a lower value. The Tempcore process [9] includes a quenching and self-annealing step of the bar directly after finish rolling. This way, actually, medium to low carbon steels were now sufficient to fulfill the mechanical property needs, but sometimes at somewhat larger manganese values than in the past. Tempcore managed to produce rebars of minimum 500MPa yield stress, reducing albeit ductility. Its success was in the attained steel microstructure. The coexistence of different low- and high-hardness phases present in two different regions across the section, which were set after the Tempcore heat treatment cycle, are responsible for gaining high mechanical properties. In the outer cross-section of the bar, a martensitic or bainitic structure occurs depending upon the quenching rate. In the inner region of the bar, which occupies the biggest portion of the cross-section, the steel consists mainly from ferrite (70-75\%) and dispersed pearlite (25-30\%) within the ferritic matrix [10].

As the quench is only partial, the formed martensite or bainite is self-tempered after the exit from the baths. The ferrite grain size varies from $8-15 \mu \mathrm{m}$ in length (along the rolling direction) and $2-5 \mu \mathrm{m}$ in width. The large ferrite amount is responsible for the satisfactory elongation behavior of the steel. Furthermore, the achieved high strength levels (both yield and tensile strength) derive from the outer hard martensitic or bainitic shell. Nevertheless, due to quenching some micro-cracks can be observed at the interface between the inner and outer regions of the microstructure based on the quench severity. The twophase cross-section in conjunction with some inevitable internal defects (e.g. macro-inclusions from melting/casting) can reduce the material soundness and, therefore, can deteriorate ductility (as measured in tensile testing by percent total elongation). Due to the nature of the heat treatment (quench and temper) the rebars produced by this method potentially suffer also at high temperatures (above $550^{\circ} \mathrm{C}$ ) reducing the construction reliability after fire hazards. In addition to this, a further main issue is the achieved relatively small tensile strength-to-yield stress ratio $(\geq 1.15)$, which is very important for the building structural integrity for instance after a dynamic incident like an earthquake or a malicious action. Thus, for economic reasons, until now the CMn heat-treated rebars dominated the worldwide market.

On the other hand, Vanadium (V) addition has remained for some years as the most cost-effective alternative to Tempcore for rebar production. The precipitation of vanadium nitrides (VN) during hot rolling contributes mostly to the ferritic matrix strengthening. At a somewhat higher cost, the product exhibits increased ductility and withstands soft temperature effects in a more predictable and reversible way. Recently, vanadium ferroalloys have exhibited a price increase that deteriorates their use to an extent due to cost reasons. Furthermore, Niobium ( $\mathrm{Nb}$ ) is well-known for many years as a major grain refiner in steel. It exhibits not only a cost-effective production but also an improved grain-refinement effect through a more complex precipitation process, as well; it shows a less negative effect to weldability, especially unlike V. Although chemistry-based, micro-alloyed rebars have been produced for many years without $\mathrm{Nb}$ as the main metallic constituent. Nevertheless, it is now the most attractive period for its further utilization. The existing need for the constructions to endure extreme conditions, to sustain higher loads and bending moments, can pave the way for its application [11]. Nb-based micro-alloyed steels offer significant benefits, such as a very refined microstructure, a variety of precipitates with the majority being smaller than $1 \mu \mathrm{m}$, ability to co-alloy with Molybdenum (Mo) that can increase fire resistance as a consequence of molybdenum carbides (MoC), that do not decompose in the temperature region of a fire $\left(800-1000^{\circ} \mathrm{C}\right)$. Taking into account the raw material availability and the competing pricing policy, $\mathrm{Nb}$ most definitely will play a paramount role as a main strengthening additive in the near future. Furthermore, Nb requires half the $\mathrm{V}$ percentage for similar strengthening effects [3]. Actually, $\mathrm{Nb}$ acts mainly as a grain refiner and it is for a long time verified that the yield stress is related to the mean grain size by the Hall-Petch equation (eq. 2):

$$
Y S_{H P}=K d^{-1 / 2} \text { with } K=17.9 \mathrm{MPa} \mathrm{mm}^{1 / 2}
$$

From eq. 2, one can easily calculate that if the addition of $0.01 \mathrm{wt} \% \mathrm{Nb}$ can reduce the mean ferritic grain-size from $12 \mu \mathrm{m}$ to $9 \mu \mathrm{m}$, the YS can increase by about $25 \mathrm{MPa}$. Depending on the desired YS level, low or medium-low carbon steels can be chosen. Then, by selecting the degree of steel cleanliness e.g. Sulfur (S) $<70 \mathrm{ppm}$, Phosphorus (P) $<0.02 \mathrm{wt} \%$, with $\mathrm{Nb}$ levels around $0.025-0.035 \mathrm{wt} \%$, and a properly controlled cooling scheme (ACC: accelerated cooling) just after rolling, an optimized grain size can be attained. In this manner, rebar (as well as plate) grades with YS above 600 MPa can be produced at a predefined level of cost. Similar ideas hold true for the production of steel plates for construction purposes. In this case, a uniform grain size distribution within the cross-section of a plate is critical for superior ductility and impact strength at low temperatures. The degree of steel cleanliness and proper roll-pass design are fundamental issues for the optimization of the final product properties. Although a parallel to Tempcore process was not required for the development of high strength plates, proper water-cooling processes were designed in order to adjust the final plate microstructure with aimed prevailing phases like pearlite, bainite, or acicular ferrite. Table 2 illustrates the salient features of indicative chemical analyses for plates and rebars that are expected to play some role in the near future. The addition of Mo has the potential to increase the fire resistance of steel, while Titanium (Ti) and Boron (B) give rise to increased strength; Ti also behaves as nitrogen (N) scavenger saving part of $\mathrm{Nb}$ for its main grain refining and precipitationhardening role [12]. 


\section{Civil Engineering Research Journal}

Table 2: Indicative chemical analyses for specific purpose carbon steels.

\begin{tabular}{|c|c|c|c|c|c|c|c|c|c|c|c|}
\hline Shape & YS & C & Mn & $\mathbf{N i}$ & $\mathrm{Cr}$ & $\mathrm{Nb}$ & $\mathbf{v}$ & Mo & $\mathbf{T i}$ & B & $\mathbf{S}$ \\
\hline & MPa & \multicolumn{7}{|c|}{ wt $\%$} & \multicolumn{3}{|c|}{ ppm, max } \\
\hline Plate & 450 & .06 & 1.60 & .30 & .50 & .05 & - & .10 & 200 & - & 60 \\
\hline Plate & 650 & .08 & 2.0 & .20 & - & .06 & - & .50 & 350 & 20 & 60 \\
\hline Plate & 630 & .16 & 1.2 & .80 & .80 & .05 & .60 & .60 & 150 & - & 150 \\
\hline Plate & 800 & .20 & 3.0 & 2.0 & .80 & .12 & .12 & .60 & 350 & - & 60 \\
\hline Plate & 900 & .08 & .80 & 2.0 & .60 & .09 & .04 & .50 & 20 & 5 & 35 \\
\hline Beam & 500 & .10 & .85 & .10 & .10 & .03 & .02 & .05 & - & - & 150 \\
\hline Rebar & 600 & .28 & 1.0 & - & - & .02 & - & - & - & - & 420 \\
\hline Rebar & 500 & .20 & 1.25 & - & - & .06 & .06 & - & - & - & 50 \\
\hline Rebar & 500 & .20 & 1.25 & - & - & .06 & .06 & - & - & - & 50 \\
\hline Rebar & 500 & .07 & 1.10 & - & - & .07 & - & - & - & - & 50 \\
\hline Rebar & 690 & .07 & 1.30 & - & - & .05 & - & - & 600 & 25 & 50 \\
\hline Rebar & 690 & .04 & 1.80 & - & - & .06 & - & .30 & 200 & 20 & 50 \\
\hline
\end{tabular}

\section{Conclusion}

Concluding, higher buildings, constructions that survive in corrosive environments (e.g. near to the sea level), general safety needs for fire resistance, design considerations that include improved forming and strength levels, product related needs (cutto-length, coiling etc.), put the traditionally applied construction steel-grades under severe scrutiny. The need for tailored, more homogeneous microstructures with improved mechanical and technological properties, pave the way for the utilization of micro-alloyed steel bar and plate products mainly using $\mathrm{Nb}$ and/or $\mathrm{NbTi}$ and/or NbTiMo as the main alloying strategies. Nevertheless, $\mathrm{V}$ may also complement the $\mathrm{Nb}$ additions and may serve as a progressive strength-increment factor that can forgive temperature variations during thermo-mechanical processing.

\section{References}

1. Small JC, Poulos HG (2003) 1.11 Structural Integrity Issues Associated with Soils and Rock in Civil Engineering Industries. in Comprehensive Structural Integrity (1): 217-239.

2. Harrison J, Hamza M (2017) Case Histories in the Application of Structural Integrity Analysis in the Oil Industry. Reference Module in Materials Science and Materials Engineering 1-12.

3. Maalekian M (2007) The Effects of Alloying Elements on Steels (I). Technische Universität Graz, Austria.

4. Jones L, Knox K, Thomas GL, Erskine W (2000) High Strength Hot Rolled CMn and CMnSi steels: Processing, Properties and Performance. Thermomechanical Processing of Steels 24(5): 361
5. Rashid MS (1980) High-strength, low-alloy steels. Science 208 (4446): 862-869.

6. Mishra S, Das S, Ranganathan S (2002) Precipitation in high strength low alloy (HSLA) steel: a TEM study. Materials Science and Engineering A 323(1-2): 285-292.

7. Magallon G, Molina C, Lopez D, Martinez L (1991) Microalloyed Steel Rebars of 590Mpa Minimum Yield Strength. International Conference on Processing, Microstructure and Properties of Microalloyed and Other Modern High Strength Low Alloy Steels, Pittsburgh, Pennsylvania, USA.

8. Baker TN (2016) Microalloyed steels. Ironmaking \& Steelmaking 43(4): 264-307.

9. Niño O, Martínez D, Lizcano C, Guerrero-Mata M Colás R (2007) Study of the Tempcore Process for the Production of High Resistance Reinforcing Rods. Materials Science Forum (537-538): 533-540.

10. Bała P (2009) Tempcore Process Analysis based on the Kinetics of Phase Transformations. Archives of Metallurgy and Materials 54(4): 1223-1230.

11. Gutiérrez I (2013) Effect of microstructure on the impact toughness of $\mathrm{Nb}$-microalloyed steel: Generalisation of existing relations from ferrite-pearlite to high strength microstructures. Materials Science and Engineering A 571: 57-67.

12. Manohar PA, Dunne DP, Chandra T, Killmore C (1995) Grain Growth Predictions in Microalloyed Steels. ISIJ International 36(2): 194-200. 


\section{Civil Engineering Research Journal}

This work is licensed under Creative Commons Attribution 4.0 License

DOI: 10.19080/CERJ.2018.06.555692
Your next submission with Juniper Publishers will reach you the below assets

- Quality Editorial service

- Swift Peer Review

- Reprints availability

- E-prints Service

- Manuscript Podcast for convenient understanding

- Global attainment for your research

- Manuscript accessibility in different formats

( Pdf, E-pub, Full Text, Audio)

- Unceasing customer service

Track the below URL for one-step submission https://juniperpublishers.com/online-submission.php 